\title{
Using metacognitive strategies in teaching to facilitate understanding of light concepts among Year 9 students
}

Background: Enhancing students' metacognitive abilities will help to facilitate their understanding of science concepts.

Purpose: The study was designed to conduct and evaluate the effectiveness of a repertoire of interventions aimed at enhancing secondary school students' metacognitive capabilities and their achievements in science.

Sample: A class of 35 students from Year 9 participated in the study.

Design and methods: The study involved a pre-post design, conducted by the first author as part of the regular designated science program in a class taught by him.

Interventions: In order to enhance the students' metacognitive capabilities, the first author employed clearly stated focused outcomes, engaging them in collaborative group work, reading scientific texts and using concept mapping techniques during classroom instruction. The data to evaluate the effectiveness of the metacognitive interventions were obtained from pre- and posttest results of two metacognitive questionnaires, the Metacognitive Support Questionnaire (MSpQ) and the Metacognitive Strategy Use Questionnaire (MStQ), and data from interviews. In addition, pre-test and post-test scores were used from a two-tier multiplechoice test on Light.

Results: The results showed gains in the $M S p Q$ but not in the $M S t Q$. However, the qualitative data from interviews suggested high metacognitive capabilities amongst the high and average achieving students at the end of the study. Students gains were also evident from the test scores in the Light test.

Conclusion: Although the quantitative data obtained from the Metacognitive Strategies Questionnaire did not show significant gains in the students' metacognitive strategies, the 
qualitative data from interviews suggested positive perceptions of students' metacognitive strategies amongst the high and average achieving students. Data from the Metacognitive Support Questionnaire showed that there were significant gains in the students' perceptions of their metacognitive support implying that the majority of the students perceived that their learning environment was oriented towards the development of their metacognitive capabilities. The effect of the metacognitive interventions on students' achievement in the Light test resulted in students displaying the correct declarative knowledge but quite often they lacked the procedural knowledge by failing to explain their answers correctly.

Keywords: assessments; metacognition; light concepts; secondary science achievement

\section{Introduction}

The term metacognition emerged from the early work of Flavell who referred to it as knowledge concerning one's own cognitive processes and products or anything related to them (Dutke, Barenberg and Leopold 2010; Phelps, Ellis and Hase 2001). Psychological and educational research literature over the past two decades consider metacognition to be key to deeper, more durable and more transferable learning (Dutke, Barenberg and Leopold 2010; Huff and Nietfeld 2009). Metacognition involves awareness of one's thinking, active monitoring of cognitive processes, regulation of cognitive processes, and application of heuristics to organise problem solving. Metacognitive strategies are employed by a person in a process of purposeful inquiry (Schraw 2009). Thus, there is much promise that interventions aimed at enhancing student metacognition might lead to corresponding improvements in conceptual understanding of curricula content.

\section{Theoretical framework}




\section{Students' metacognitive capabilities}

The conceptual framework for the investigation of the effectiveness of a repertoire of interventions to enhance students' metacognitive capabilities and their achievements in science has its roots in cognitive psychology. In this study, the metacognitive interventions employed have been derived from two metacognitive models: the metacognitive model of self-regulated learning of Pintrich (2000) and the socio-cognitive model of self-regulated learning espoused by Zimmerman and Schunk (2001). According to Pintrich (2000), selfregulated learning, as a component of metacognition, is an active, constructive process whereby students set goals for their learning and then attempt to monitor, regulate and control their cognition, motivation and behaviour guided and constrained by the goals and features in their learning environment. According to Zimmerman and Schunk (2001), metacognitive learning involves the use of numerous self-regulatory processes such as planning, knowledge activation, metacognitive monitoring and regulation and reflection (Azevedo 2009).

Although researchers have not clearly articulated a universal theoretical model of metacognition, researchers such as Veenman (2012) do propose a comprehensive theory on the nature and orign of metacognive skills. Overall, metacognition has often been conceptualised by many researchers as comprising two main sub-components referred to as knowledge of cognition and regulation of cognition (Hartman 2001; Ku and Ho 2010; Magno 2010; Schraw, Crippen and Hartley 2006; Wilson and Bai 2010; Zimmerman and Schunk 2001).

\section{Knowledge of cognition}

Knowledge of cognition, which refers to what the learner knows about him or herself as a learner and the task at hand, includes three subcomponents: declarative knowledge, procedural knowledge and conditional knowledge. Declarative knowledge is knowledge about one's own capabilities (Hartman 2001; Schraw, Crippen and Hartley 2006). Procedural 
knowledge, in contrast, refers to knowledge about how to approach a task or the difficulty of a task in terms of content or length. This involves knowledge about strategies or procedures to be used to achieve a desired goal. Procedural knowledge can be represented as a set of production rules which are condition-action pairs. For example, a student may have knowledge about the properties of light or the laws of reflection of light (declarative knowledge) but may experience difficulty in how to draw a ray diagram to determine the position of the image in a plane mirror (procedural knowledge). Procedural knowledge and declarative knowledge are often considered to be domain-specific (Schraw, Crippen and Hartley 2006; Zohar and David 2009). Finally, conditional knowledge includes knowledge of why and when to use declarative and procedural knowledge. Individuals with a high degree of conditional knowledge are better able to assess the demands of a specific learning situation and, in turn, select strategies that are most appropriate for that situation (Schraw, Crippen and Hartley 2006; Zohar and David 2009). For example, a student may be aware of the laws of reflection and refraction of light, but when presented with a question to explain why the bottom of a pool appears more shallow than it actually is, he or she has to decide which knowledge to use to explain this phenomenon (conditional knowledge).

\section{Regulation of cognition}

Regulation of cognition means the application of activities to help students to control their learning. Although there are a number of regulatory skills, the three essential skills in the classroom are: planning, monitoring, and evaluating. Planning involves the selection of appropriate strategies and effective use of resources to enhance performance. Examples include breaking down tasks into smaller manageable components, time management, being focused or blocking out any form of distraction. Monitoring refers to the ability to engage in periodic self-testing while learning. Research studies show that monitoring ability improves with training and practice. Evaluating refers to appraising the outcomes and efficiency of 
one's learning. For example, it involves analysing the learning strategies used in relation to their effect on the student's goals. Many research studies suggest that metacognitive knowledge and regulatory skills such as planning are related to evaluation (Hartman 2001; Leutwyler 2009). In summary, metacognition consists of knowledge and regulatory skills that are used to control one's cognition.

The focus of this research was on the enhancement of students' metacognitive capabilities, in order to improve their achievements in science, by conducting a repertoire of metacognitive interventions (metacognitive support). For the purpose of this research, metacognition has been compartmentalised into metacognitive strategies, metacoginitive support and students' achievements in the science classroom.

\section{Metacognitive Strategies}

The three sub-components of metacognition that are important for classroom performance are self-regulation, cognitive strategy use, and cognitive self-consciousness (Cartwright-Hatton et al. 2002; Pintrich and De Groot 1990; Thomas 2003).

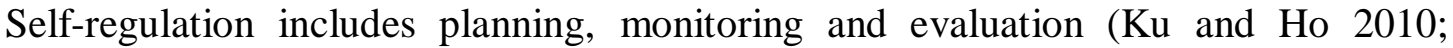
Leutwyler 2009; Magno 2010; McLoughlin and Taji 2005; Pintrich and De Groot 1990). Planning involves goal setting, activating relevant background knowledge, and budgeting time. Monitoring includes the self-testing skills necessary to control learning. Expert learners monitor at both the local level, such as an individual test items, and the global level, such as all items on a test (overall performance). Evaluation refers to appraising the products and a regulatory process of one's learning. Typical examples include re-evaluating one's goals, revising predictions, and consolidating intellectual gains ( $\mathrm{Ku}$ and Ho 2010; Magno 2010). According to Leutwyler (2009, p.113), self-regulated learning is a pro-active, intentional, and reflexive form of learning that is based on a sense of personal responsibility for learning. Self-regulated learning occurs when the learner possesses a repertoire of strategies that can be 
employed adaptively and used intentionally and include cognitive, behavioural and motivational strategies.

Cognitive strategies that students use to learn, remember and understand the concepts taught include, rehearsal, elaboration, and organisational strategies. These strategies foster active engagement in learning and result in higher levels of achievement. Examples of activities in the science classroom that require cognitive strategy use include: classifying, analysing causal relationships, carrying out scientific inquiry processes such as formulating and testing hypotheses, making generalisations or drawing a valid conclusion (Leutwyler 2009; Pintrich and Groot 1990; Zohar and David 2009).

Cognitive self-consciousness involves monitoring one's thoughts. Scores on this scale in the metacognition questionnaire developed by Pintrich (2000), have shown it to be highly correlated with measures of anxiety, particularly of worry. Selective attention to internal events is believed to be a key factor in the development of anxiety and other emotions. It is thought that reduction in cognitive self-consciousness may arise as an avoidance response. This has been evidenced by low scores on cognitive self-consciousness by young anxious people in sample studies (Cartwright-Hatton et al. 2002). Cognitive self-consciousness has a strong effect on motivational factors such as self-esteem and self-efficacy which facilitate learning, sustain effort and attention, and enable completion of activities (Leutwyler 2009).

\section{Metacognitive support}

According to Thomas $(2003,2006)$, the characteristics of a metacognitively-oriented learning environment involve five dimensions: metacognitive demands, student-student discourse, student-teacher discourse, student voice, and teacher encouragement and support.

Metacognitive demands refer to whether or not students are asked to be aware of how they learn and how they can improve their science learning. In research conducted by Thomas (2006), students' responses suggested that teachers often tell students to find ways to 
learn science but seldom explain how to learn science. In order to improve students' achievement, science teachers need to model metacognition and explicitly teach metacognitive strategies such as elaboration and organisational strategies (Pintrich and De Groot 1990; Thomas 2003).

Student-student discourses can be used to determine whether or not students discuss their science learning processes with each other. Collaborative group work is not just about learning the social skills of working together. Interactions with other students can provide the stimulus needed by individual students to become aware of their cognitive processing (Larkin 2006). Students need to be given opportunities to discuss learning itself in addition to the material to be learned. Since all students possess some metacognitive knowledge, it is important to give them opportunities to critique their metacognitive knowledge and beliefs about teaching and learning against the views of their peers as they trial new strategies. According to research conducted by Thomas (2003, 2006), student-student discussions are more often related to content and less to metacognitive strategies. Unless students are frequently given opportunities to interact in the classroom, it may be difficult for them to practice or elaborate on their metacognitive strategies (Larkin 2006).

Student-teacher discourses refer to whether or not students discuss their science learning process with their teacher. Research findings suggest that most student-teacher discussions are often about the consequences of learning and less on the processes involved (Thomas 2006). It is essential that regular discussions about learning and learning processes occur. Students need to be given opportunities to explain and discuss their metacognitive knowledge with their teacher.

Student voice refers to whether or not students feel it is legitimate to question the teacher's pedagogical plans and methods. According to research findings by Thomas (2006), many students have the perception that since the teachers plan the lessons beforehand, they 
know better and therefore do not need help to decide what to do. There is a need to create a social climate in which students benefit from questioning the teacher's pedagogical plans and methods, and are able to collaborate with the teacher to plan and assess their learning as they develop into autonomous learners and self-regulated learners. Students need to be given increased control over their classroom activities so that they can apply strategies that they have found through practice to be effective in helping them meet their learning goals (Thomas 2003).

Teacher encouragement and support refers to whether or not students are encouraged by the teacher to improve their science learning processes. Research findings suggest that teacher encouragement is often more general in nature and is not specifically related to particular metacognitive strategies (Thomas 2006). To facilitate this aspect of metacognitive support, students need to be made aware of the language of learning and encouraged to develop and use such language in their classroom as an initial step to developing a shared language of learning with their students. The aim of using such a language is to inform students about what it means to learn science, how to form opinions and make informed decisions about how they learn, how they can improve their learning, and how they can communicate with others about their processes of learning science (Thomas 2003, 2006).

In addition, environments that support metacognitive development include a number of components that are designed to function as a system in the sense that they are mutually supportive. The components are: (1) a focus on learning goals that emphasize deep understanding of important subject-matter content, (2) the use of scaffolds to support the students, (3) frequent opportunities for formative self-assessment, revision, and reflection, and (4) social organisations that promote collaboration and a striving for high standards (Greene, Costa and Dellinger 2011; Hacker, Dunlosky and Graser 1998). 
Classroom factors which limit metacognitive development include: (1) predetermined syllabus, (2) long established expectations for appropriate student participation, (3) lesson development, and (4) classroom management (Greene et al. 2011). Lastly, it is often impossible to know how students are progressing metacognitively because most academic assessments are designed to assess cognitive rather than metacognitive processing.

\section{Metacognitive interventions}

\section{Provision offocused outcomes}

Metacognitive interventions can serve as a road map to learning. Learning metacognitively is a proactive and constructive process whereby students set clear goals for their learning and monitor, regulate and control their cognition and behaviour guided by their goals (Azevedo 2009). The provision of focused outcomes, before a topic is taught, in the science classroom enhances the students' capabilities to monitor and control their learning, which fosters their metacognitive capabilities. Focused outcomes are even more beneficial if they are organised in a time-ordered sequence that the teacher and the students follow. Clearly stated focused outcomes enable students to set meaningful goals and determine which strategies to use given the task conditions. Students may also generate motivational beliefs based on their previous experiences with the concepts in the topic.

\section{Concept maps}

Early uses of concept mapping were mostly in the context of science classrooms but more recent uses have widened to explore the nature of learning in many other subject areas. Concept mapping was first developed by Novak and Gowin in the 1960s. The theoretical framework that supports the use of concept mapping is consistent with constructivist cognitive psychology. Concept mapping is a method to visualise the structure of knowledge (Asan 2007; Ritchhart, Turner and Hader 2009). A concept map is a graphical representation of the relationship among terms or concepts (Vanides, Yin, Tomita and Ruiz-Primi 2005). 
Concept maps help students to understand the relationship between concepts and reduce the need for rote learning. In other words, concept maps help students to move from a surface to a deep approach to learning. They also can enable teachers to negotiate meanings of key concepts with students and design better teaching programmes. The mental models exhibited by the students' concept maps can provide the basis for future teaching (Hartmann, 2001; Ritchhart, Turner and Hader 2009). Many other benefits of concept maps cited include, providing an effective tool for capturing students' thinking processes, understanding superordinate and sub-ordinate relationships between concepts and improving collaborative group work. Concept maps also help students and teachers to distinguish misconceptions from valid conceptions, reduce anxiety and improve self-confidence. Lastly, concept maps also naturally integrate literacy and science by providing a starting point for writing scientific terms. Especially young and low achieving students who still struggle with spelling scientific words benefit greatly from concept mapping. According to research, middle school science students taught to use concept maps performed better on tests than students who were not taught these strategies. This is because students remember information better when it is represented and learned both visually and verbally (Asan, 2007; Hartmann, 2001; Ritchhart, Turner and Hader 2009; Vanides et al. 2005).

Collaborative group work

One aspect of collaborative group work in science involves students doing experiments and using the results for shared knowledge construction. Interactions with others can provide the stimulus needed for individuals to become aware of their cognitive processing. Collaborative group work is not just about learning the social skills of working together, or learning the language of explanation and negotiation. Students need to understand and agree with contributions of their peers in order to construct knowledge together. It is also about providing opportunities for and provoking the need for students to reflect on their thinking. It 
is about constructing new thoughts and collaborating to understand and influence the cognitive and motivational states of oneself and others. Merging collaborative learning with inquiry learning can support students' inquiry learning process and improve their learning performance (Saab, Van Joolingen and Van Hout-Wolters 2011). Unless students are given opportunities to interact with others at a substantive cognitive level it may be difficult for them to practice or elaborate on metacognitive strategies or to gain feedback about their own cognitive processing (Larkin 2006).

However, students often find it difficult to go through the inquiry process efficiently. Collaboration without means of support does not necessarily lead to an effective collaborative learning process. There is need to provide a set of communication guidelines which support students' collaboration process. These guidelines could include sentence openers that structure students' communication, tools that can be used to present a shared conception of the problem whereby students externalise their ideas based on this shared conception. Explanation Builder and the Collaborative Hypothesis Tool are examples of tools that support both the inquiry learning process as well as the collaborative process (Saab, Van Joolingen and Van Hout-Wolters 2011).

\section{Reading scientific texts}

Research by Cook-Sather (2011) suggests that students who do not understand the structure of scientific texts have problems representing the material, thereby impeding comprehension and retention. Comprehension of complex science topics occurs from the creation of new understanding of the information by the learner. However, learners are not very successful generating their own meaning because they rarely regulate their own learning process cognitively or metacognitively (Hyeon et al. 2009). Comprehension and understanding result from the generation of relations both among concepts and between experience or prior learning and information. That is comprehension occurs from the creation of new 
understandings of the information by the learner, rather than transferring the presented information (Hyeon 2009). The most frequently used learning strategies employed are underlining and note-taking. Adjunct questioning is another strategy that has been consistently considered as a generative activity. Students who are allowed to underline text that they considered most relevant performed better on the post test. Research has also showed that students who generated paragraph summaries significantly increased their retention (Cook-Sather, 2011). Therefore, it is important for instructional designers or teachers to consider metacognitive scaffolding during leaners' generation process. Secondly, to generate relationships among or between new information and memory, learners need to rehearse, elaborate, organize and synthesize the information. In doing so learners become proficient in regulating their learning process (Hyeon 2009).

\section{Purpose of study and research questions}

The purpose of this study was to implement metacognitive strategies and investigate students' metacognitive capabilities and to assess the correlation between their metacognitive capabilities and achievement in science tests. The following research questions were addressed to achieve the purpose of this study.

1. What was the effect of the interventions on students' use of metacognitive strategies?

2. What was the effect of the interventions on the students' perceptions of metacognitive support?

3. What was the effect of the metacognitive interventions on students' achievements in the Light conceptual test?

\section{Methodology}

Research design and sample 
The research, which involved a pre-post design with no control group (Anderson, 2004) investigated the effectiveness of a repertoire of interventions to enhance secondary students' metacognitive capabilities and achievement in science. A control group could not be used due to the sensitivity of the other teachers who did not like making comparisons with their students' achievements. Furthermore, the first author taught only one Year 9 class. The study was conducted by the first author as part of the regular designated science program to assess 35 Year 9 students' metacognitive capabilities in a class taught by him. The classes in the school had a relatively small number of students.

\section{Interventions}

In order to enhance the students' metacognitive capabilities, the first author employed several interventions that included providing students with focused outcomes, organising collaborative activities and enhancing their skills in reading scientific text, and drawing concept maps during classroom instruction (see Figure 1). The interventions were conducted over 6 weeks totalling 33.3 hours of curriculum time. 


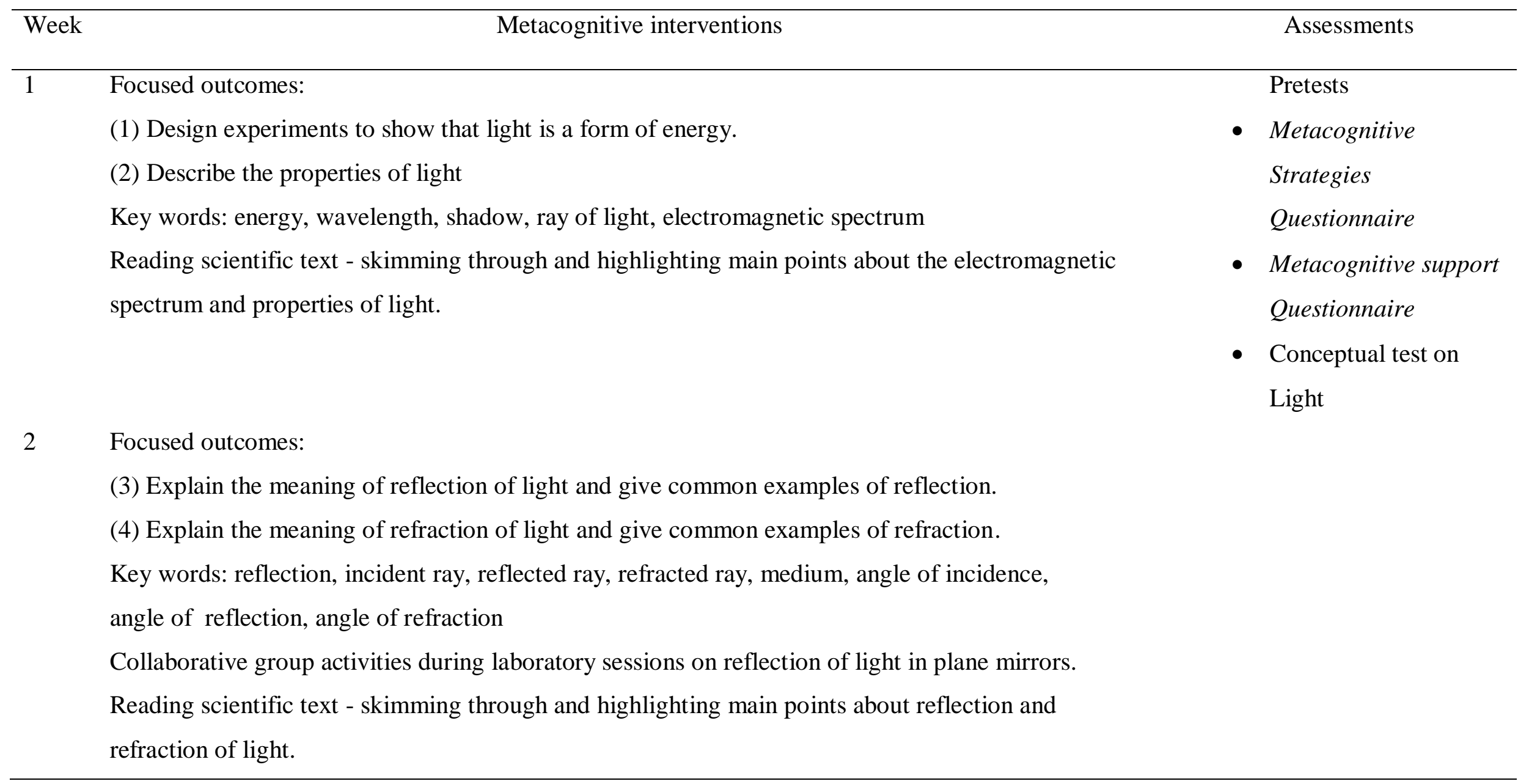


$3 \quad$ Focused outcomes:

(5) Use ray diagrams to illustrate refraction of light in lenses.

(6) Explain the meaning of dispersion of light

Key words: Concave lens, convex lens, focal point, focal length, spectrum, dispersion, prism, rainbow

Collaborative practical activities involving variation of object distance and its effect on image distance; and measuring the focal length of various concave and convex lenses.

Focused outcomes:

(7) Use diagrams to illustrate the dispersion of white light by a triangular prism.

Collaborative group activities involving discussions of questions related to theoretical concepts about refraction, dispersion of light and the formation of rainbows.

5 Group work (3 students per group) to draw concept maps using any 10 keywords on light. Individual work to make concept maps using all key words on light. 


\begin{tabular}{|c|c|c|}
\hline Week & Metacognitive interventions & Assessments \\
\hline $7-9$ & Completion of other topics in the scheme of work for the semester. & \\
\hline 10 & Revision & $\begin{array}{l}\text { Posttests } \\
\text { - Metacognitive } \\
\text { Strategies } \\
\text { Questionnaire } \\
\text { - Metacognitive support } \\
\text { Questionnaire }\end{array}$ \\
\hline
\end{tabular}

Figure 1 Details of the instructional program to enhance students' metacognitive capabilities 
Students were given clearly written focused outcomes listed in Figure 1 at the beginning of the topic and were instructed to attach them in their workbooks at the start of the topic in this study. Students were also given key words or concepts at the beginning of the topic. The researcher always instructed the students to mark-off the outcomes covered after a lesson was conducted. Students were encouraged to use the focused outcomes as a checklist when preparing for a test and also to find the meanings of the keywords in the topic.

Collaborative group activities were conducted in the theoretical or practical lessons (when doing experiments) at least once a week. Students were encouraged to discuss phenomena without writing down their ideas. During experiments students were instructed to take turns to set up the equipment and make observations in their experiments while discussing their inferences. Verbal thinking was encouraged during group discussions,

Concept maps were used at the end of the topic to make connections between key words in the topic. Students were encouraged to use the keywords provided at the beginning of each topic to construct concept maps. Students were reminded that there were many ways to construct concept maps and that this was a useful tool to summarise the major concepts in a topic and revise for a science test.

Students were often given texts to read followed by answering questions. They were encouraged to skim through the text first followed by reading slowly and underlining or highlight major concepts, make summaries in their own words and write out questions next to relevant texts (adjunct questioning). In some instances student were given summary notes related to text, with gaps to fill in.

\section{Ethical considerations}

The stduents were informed at the beginning that a record of the teaching and learning were part of a study that the first author was conducting . They were informed that their names would not be refererred to in any materials that would be used in any publications. (Curtin 
University Human Research Ethics Committee approval number SMEC-07-09 dated 28 March 2012).

\section{Measuring metacognitive capabilities}

\section{Quantitative data collection}

In order to assess students' metacognitive capabilities the authors used two metacognitive surveys at the beginning (pre-metacognitive survey) and at the end (post-metacognitive survey) of the study. The survey questionnaires were used to identify students' perceptions of the metacognitive strategies and support that they received in the classroom. One of these questionnaires, the Metacognitive Strategies Questionnaire (MStQ), consisted of 28 items in three scales - Cognitive Strategy Use (CSU), Self-Regulation (SR), Cognitive Selfconsciousness (CSC). The other questionnaire, the Metacognitive Support questionnaire $(M S p Q)$, consisted of 25 items in five scales - Student-Student Discourse (SSD), StudentTeacher Discourse (STD), Student Voice (SV), Metacognitive Demand (MD). and Teacher Encouragement and Support (TES). The items in the scales were scored using a Likert-type scale ranging from 1 to 5 to represent students' perceptions, with 1 representing 'almost never', 2 for 'seldom', 3 for 'sometimes', 4 for 'often', and 5 for 'very often'. The questionnaires were administered as a pre-test before commencement of the study and again as a posttest at the end of the interventions. Students were given 50 minutes to respond to both the questionnaires. Both questionnaires are found in the Electronic Supplementary Materials (ESM).

\section{Qualiatatitave data collection (Semi-structured Interviews)}

In this study, semi-structured written interviews were used to interview students of varying abilities. Twelve students from Year 9 were interviewed. Students of high and average achieving levels provided information independently whereas the low achieving students were given a lot of support. The interview questions were developed from the metacognitive 
surveys so that students could elaborate on their responses, which was not possible in the survey. Table 1 shows some of the semi-structured questions that were used in the metacognitive interviews.

Table 1 Semi-structured Metacognitive Interview Questions used in this Study

\begin{tabular}{ll}
\hline Metacognitive strategies scale & \multicolumn{1}{c}{ Sample question } \\
\hline Self-regulation (SR) & $\begin{array}{l}\text { When you are preparing for a test, do you } \\
\text { usually try to put together notes from class or } \\
\text { text books? }\end{array}$ \\
Cognitive Strategy Use (CSU) & $\begin{array}{l}\text { How do you know that you remember } \\
\text { material covered in class? }\end{array}$ \\
Cognitive Self-consciousness (CSC) & $\begin{array}{l}\text { When you are solving a problem in a science } \\
\text { class, are you aware of your thinking? }\end{array}$ \\
\hline
\end{tabular}

\section{Measuring understanding of Light concepts}

Students' understanding of the concepts of light were measured by a two-tier diagnostic test that examined reflection and refraction concepts. The test was designed to meet the goals of the implemented school curriculum based on optics items from $\mathrm{Chu}$, Treagust, and Chandrasegaran (2009). An example, of one such item is shown in Figure 2. The complete test is shown in the Electronic Supplementary Materials (ESM). 


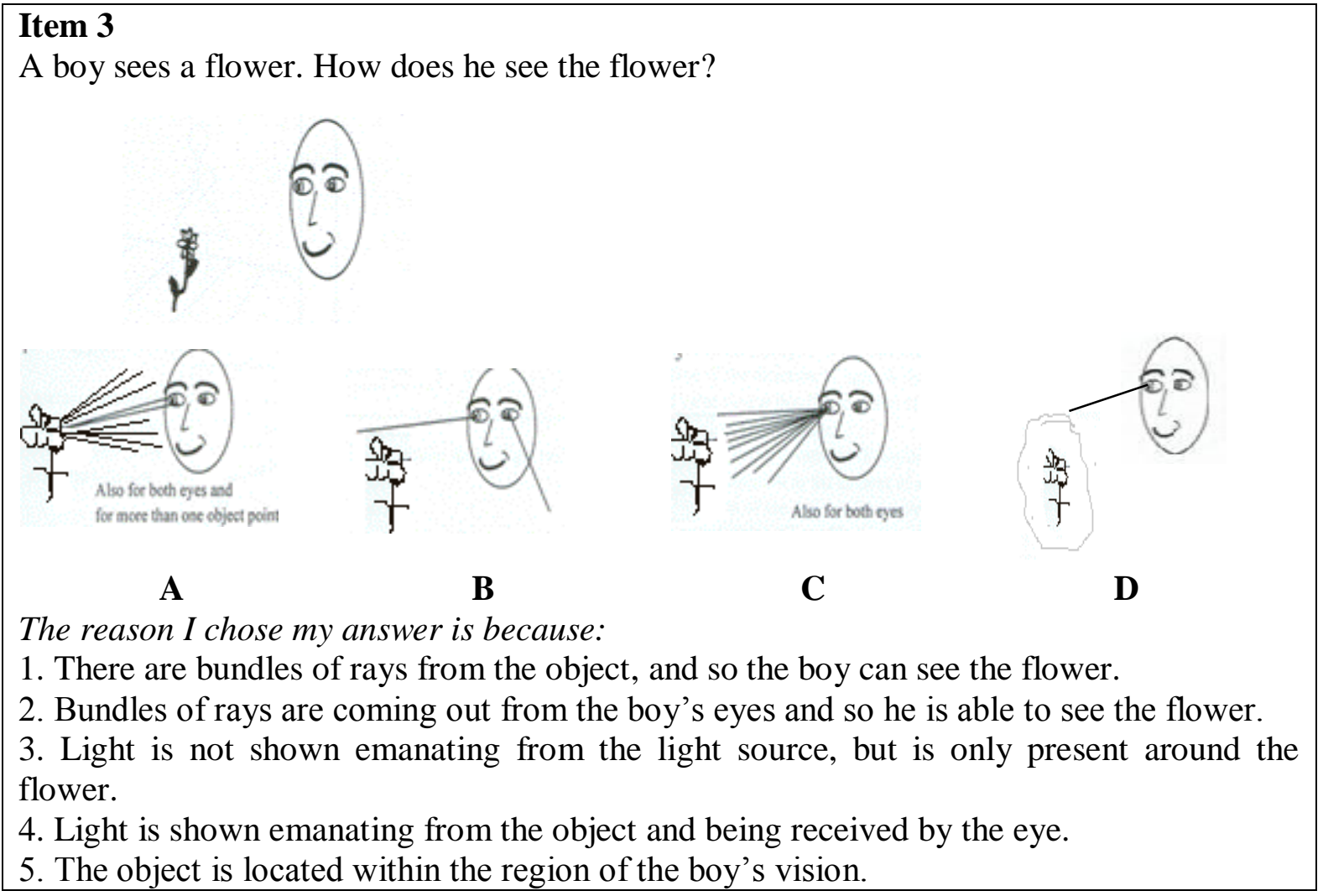

Figure 2 Example of Item 3 in the light pre-post test

\section{Data analyses procedures}

After the students had responded to the questionnaires and the Light test, their responses were entered into a data file. SPSS software (version 20) was then used to analyse the Cronbach's alpha reliabilities, the means and the standard deviations of the scales in the questionnaires as well as to analyse the results of the Light test. Comparisons between the pre-test and post-test results were made using paired samples t-tests and by computing effect sizes. Students were required to select a correct answer from the first tier and give a reason by selecting an answer from the second tier. Responses to an item were considered to be correct if students provided correct responses to both tiers; these correct responses were coded ' 1 '. All other responses were considered incorrect and coded ' 0 '. The lower performance in the combined tier responses, in both the pretest and posttest indicates that students experienced difficulty in explaining scientific concepts even though they were able to select the correct 
answer in the first tier. Each test consisted of 10 two-tier multiple-choice items. An example of an item from the test is given in Figures 2. The complete instruments are found in the ESM.

The qualitative data were obtained from written interviews and analysed by using typologies (low, average and high achievers) and the same scales as those in the metacognitive surveys shown in Table 1. Students' responses were recorded in a table under the appropriate scale (cognitive strategy use, self-regulation or cognitive self-consciousness) and later a structural analysis was conducted (searching for patterns).

\section{Results and discussion}

The results of the analyses of students' responses to each of the questionnaires are summarised in Tables 2 and 3.

Table 2 Analyses of responses to the Metacognitive Strategies Questionnaire (MStQ) $(\mathrm{N}=$ 34)

\begin{tabular}{|c|c|c|c|c|c|c|c|c|c|}
\hline \multirow[t]{2}{*}{ Scales } & \multirow{2}{*}{$\begin{array}{c}\text { No. } \\
\text { of } \\
\text { items }\end{array}$} & \multicolumn{2}{|c|}{$\begin{array}{l}\text { Cronbach's } \\
\text { alpha } \\
\text { reliability }\end{array}$} & \multicolumn{2}{|c|}{ Means } & \multicolumn{2}{|c|}{$\begin{array}{l}\text { Standard } \\
\text { deviation }\end{array}$} & \multirow[t]{2}{*}{$\begin{array}{c}\mathrm{t}- \\
\text { value }\end{array}$} & \multirow[t]{2}{*}{$\begin{array}{l}\text { Effect } \\
\text { size }\end{array}$} \\
\hline & & Pre & Post & Pre & Post & Pre & Post & & \\
\hline Cognitive Strategy Use & 13 & 0.68 & 0.65 & 3.62 & 3.45 & 0.52 & 0.43 & 1.32 & 0.35 \\
\hline Self-Regulation & 9 & 0.43 & 0.61 & 3.18 & 3.01 & 0.44 & 0.41 & $2.22 * *$ & 0.39 \\
\hline $\begin{array}{l}\text { Cognitive Self- } \\
\text { Consciousness }\end{array}$ & 6 & 0.81 & 0.86 & 3.64 & 3.24 & 0.80 & 0.78 & $2.43 * *$ & 0.51 \\
\hline
\end{tabular}

Students' use of metacognitive strategies (see Table 2) before the intervention for three of the scales - Cognitive Strategy Use, Self-Regulation and Cognitive SelfConsciousness - were relatively high with mean scores above 3 indicating a general positive perception of metacognitive strategies in science by the students. Following the intervention, 
students' scores on these three scales had decreased, suggesting a lower perception of their use of metacognitive strategies following the intervention. For two of the scales these differences were statistically significant $(p<0.01)$. Three of the scales had acceptable Cronbach's alpha values except for the Self-Regulation scale in the pretest; the relatively low pretest value for the reliability may be attributed to limited understanding prior to implementation of the metacognitive strategies.

Table 3 Analyses of responses to the Metacognitive Support Questionnaire $(M S p Q)(\mathrm{N}=34)$

\begin{tabular}{|c|c|c|c|c|c|c|c|c|c|}
\hline \multirow[t]{2}{*}{ Scales } & \multirow[t]{2}{*}{$\begin{array}{l}\text { No. of } \\
\text { items }\end{array}$} & \multicolumn{2}{|c|}{$\begin{array}{l}\text { Cronbach's } \\
\text { alpha } \\
\text { reliability }\end{array}$} & \multicolumn{2}{|c|}{ Means } & \multicolumn{2}{|c|}{$\begin{array}{l}\text { Standard } \\
\text { deviation }\end{array}$} & \multirow[t]{2}{*}{$\begin{array}{c}\mathrm{t}- \\
\text { value }\end{array}$} & \multirow[t]{2}{*}{$\begin{array}{l}\text { Effect } \\
\text { size }\end{array}$} \\
\hline & & Pre & Post & Pre & Post & Pre & Post & & \\
\hline $\begin{array}{l}\text { Student-Student } \\
\text { Discourse }\end{array}$ & 5 & 0.87 & 0.83 & 1.94 & 2.32 & 0.82 & 0.72 & $3.10 * *$ & 0.49 \\
\hline $\begin{array}{l}\text { Student-Teacher } \\
\text { Discourse }\end{array}$ & 5 & 0.91 & 0.87 & 2.42 & 3.15 & 0.98 & 0.75 & $4.06^{* *}$ & 0.84 \\
\hline Student Voice & 5 & 0.66 & 0.45 & 3.90 & 4.26 & 0.63 & 0.54 & $2.96^{* *}$ & 0.61 \\
\hline $\begin{array}{l}\text { Metacognitive } \\
\text { Demands } \\
\text { Teacher }\end{array}$ & 5 & 0.72 & 0.72 & 2.61 & 3.42 & 0.75 & 0.66 & $7.87 * *$ & 1.14 \\
\hline $\begin{array}{l}\text { Encouragement and } \\
\text { Support }\end{array}$ & 5 & 0.82 & 0.93 & 3.60 & 4.14 & 0.87 & 0.86 & $2.51 * *$ & 0.62 \\
\hline
\end{tabular}

$* * p<0.01 ; \mathrm{ES}-$ effect size

Note: Cohen (1988) has defined the effect size as being small when $d=0.2$, medium when $d=0.5$ and large when $d=0.8$.

When comparing the mean scores of the four scales for Metacognitive Support as shown in Table 3, two scales had high initial scores - Student Voice (mean $=3.90)$ and Teacher Encouragement and Support (mean $=3.60)$. The other two scales - Student-Teacher Discourse $($ mean $=2.42)$ and Student-Student Discourse $($ mean $=1.94)$, with lower pretest means suggest that students did not often engage in discussions with their teacher nor with each other in collaborative or group activities in the science classroom before the interventions. Following the interventions, students' mean scores on all four scales increased 
and these differences were statistically significant suggesting that the students perceived that they received metacognitive support during the interventions. Three of the scales had acceptable Cronbach's alpha values. An indication that the intervention had some impact was evident in the Metacognitive Demands scale: the mean score was low at the outset (item mean score 2.61), but increased statistically significantly $(p<0.01)$ after the interventions, with a very large effect size of 1.14 .

Analyses of students' responses to the pretests and post-tests on the Light instrument are summarised in Table 4.

Table 4 Percentage of Year 9 students responding correctly to the first tier and both tiers of the items in the Light test $(\mathrm{N}=35)$

\begin{tabular}{lcccc}
\hline Item number & \multicolumn{2}{c}{ Pre-test } & \multicolumn{2}{c}{ Post-test } \\
\cline { 2 - 5 } & First tier only & Both tiers & First tier only & Both tiers \\
\hline 1 & 88.6 & 71.4 & 85.7 & 68.6 \\
2 & 82.9 & 54.3 & 97.1 & 62.9 \\
3 & 42.9 & 22.9 & 82.9 & 40.0 \\
4 & 48.6 & 31.4 & 91.4 & 40.0 \\
5 & 88.6 & 40.0 & 100 & 71.4 \\
6 & 60.0 & 31.4 & 74.3 & 57.1 \\
7 & 37.1 & 37.1 & 77.1 & 74.3 \\
8 & 60.0 & 60.0 & 85.7 & 85.7 \\
9 & 85.7 & 55.2 & 94.3 & 42.9 \\
10 & 85.7 & 68.6 & 97.1 & 82.9 \\
\hline
\end{tabular}

The results show that for all items (except Item 8 in the pre-test) the combined tiers responses were higher than for the first tier only. Also, except for Item 1, the tier 1 responses in the post-test were higher than in the pre-test; except for Items 1 and 8, the combined tiers responses in the post-test had improved compared to those in the pre-test. 
Table 5 displays the results of paired samples t-tests analyses of the Light pre- and post-tests with significant gains in the first tier: [Mean Difference $=2.06, \mathrm{t}(34)=5.96, p<$ 0.01] and combined tiers: [Mean Difference $=2.14, \mathrm{t}(34)=4.28, p<0.01$ ]

Table 5 Paired samples t-tests analyses of Year 9 pre- $\&$ post-tests on light $(\mathrm{N}=35)$

\begin{tabular}{lcccccc}
\hline \multirow{2}{*}{ Tier } & \multicolumn{2}{c}{ Mean } & & \multicolumn{2}{c}{ SD } & Difference \\
\cline { 2 - 3 } \cline { 5 - 6 } & Pre & Post & & Pre & Post & (t-value) \\
\hline $\begin{array}{l}\text { First tier } \\
\text { only }\end{array}$ & 6.80 & 8.86 & & 1.78 & 1.68 & $* * 5.96$ \\
\hline $\begin{array}{l}\text { Combined } \\
\text { tiers }\end{array}$ & 4.20 & 6.34 & & 1.92 & 2.87 & $* * 4.28$ \\
\hline$* * p<0.01$ & & & & & & \\
\end{tabular}

Note: maximum score for the test is 10

Generally, there were statistically significant gains in correct responses to the pre- and post-tests for both the first tier alone and when both tiers were taken into account. The findings suggest that at the beginning students in general provided correct answers to the first tier (declarative knowledge) but were in many cases unable to choose the correct scientific explanations of phenomena (procedural knowledge). Scientific explanations require the use of procedural knowledge; therefore, this data analysis suggests that the students' procedural knowledge was not well developed before the metacognitive interventions. Students' responses to the combined tiers of the pre- and post-tests showed reasonably high Cronbach's alpha reliabilities $\left(\alpha_{\text {pre }}=0.73 ; \alpha_{\text {post }}=0.79\right)$ despite the small sample size $(\mathrm{N}=35)$. The high standard deviations suggest a higher than expected variability in the mean scores that could be attributed to the relatively small sample size.

\section{Qualitative Data Analysis - Interviews About Students' Metacognitive Strategies}

Interviews relating to students' metacognitive strategies were conducted after implementation of the interventions. In this study students provided written answers to the interview 
questions. The participants were drawn from the low, average and high achieving sections of the classes in order to analyse the variations in students' metacognitive strategies in relation to their achievements in science.

\section{Cognitive strategy use}

The perceptions elicited from the high performance students indicated that they studied their class notes, answered revision questions, and if they had textbooks they used them to supplement their notes or used the internet to do some research. The average and low achieving students' responses all indicated that they solely depended on the class notes, and used repetition and rote memorisation of facts when preparing for science tests. The following are examples of students' responses to the question: Do you try to put together information from class and from the book when studying for a test?

Student 1 (high achieving): It depends on whether I have a textbook with me when I'm studying; I usually go over the notes I have taken in class and do revision questions on them.

Students 3 (average achieving): The way I prepare for a test is by reading my notes and then typing it up on my computer.

Student 4 (low achieving): To help me in a test, I make up palm cards and try to remember the facts in my head.

\section{Self-regulation}

The high and average achieving Year 9 students' responses were similar in terms of strategies employed in the learning process. Most of the high and average achieving students relied on classmates or family members to ask them questions in order to ensure they memorised material. However, the low achieving students were inconsistent in their effort to ensure that they remembered the material. Most of the low achieving students responded that they only sometimes tried to memorise. All the participants seemed to have a limited repertoire of 
cognitive strategies. The following are examples of students' responses to the question: Do you ask yourself questions to make sure you know the material?

Student 1 (low achieving): Yes sometimes but not usually.

Student 2 (average achieving): Yes, I do ask make-up questions but I ask someone else to ask the questions.

Student 3 (high achieving): I get friends to test me before the test.

\section{Cognitive self-consciousness}

Contrary to the gains in the $M S t Q$, students of all abilities responded that they were not always aware of their thinking during the learning the process. Both the average and high achieving students responded that they were sometimes aware of their thinking. The following are examples of students' responses to the question: During science classes are you constantly aware of your thinking?

Student 1 (low achieving): When I come to class I don't think about what topic we are learning in class.

Student 2 (average achieving): Sometimes I am aware of my thinking but I mostly do it subconsciously.

Student 3 (high achieving): Not always. If I'm trying hard to understand something I try to be aware of my thinking but otherwise I usually don't need to.

\section{Conclusions, limitations and recommendations}

With respect to RQ 1 (What was the effect of the interventions on students' use of metacognitive strategies?), According to the quantitative data obtained from the Metacognitive Strategies Questionnaire it may be concluded that there were no significant gains in the students' metacognitive strategies whereas the qualitative data from interviews suggested positive perceptions of students' metacognitive strategies amongst the high and average achieving students. The quantitave data findings are consistent with the research 
findings by Leutwyler (2009) which showed that there was no overall development in students' use of self-reported metacognitive strategies when they were in high school. However, this study also contradicts the research findings by Veenman, Wilhelm and Beishuizen (2004) that showed a linear increase in the use of metacognitive strategies between the age of 14 and 22. This is because the studies by Veenman, Wilhelm and Beishuizen (2004) and Veenman and Spans (2005) used on-line methods, such as observation and think-aloud protocols, for assessing the use of metacognitive strategies whereas the Leutwyler (2009) study used data obtained from off-line methods, such as interviews and questionnaires. This result suggests that off-line or self-report data reveal different aspects of metacognition from data obtained by using on-line methods. According to Schellings (2011), off-line measures are conducted before or after task performance whereas on-line measures are conducted during task performance. The large proportion of low achieving students could also have been a contributory factor to the lack of significant gains in the students' perceptions of their metacognitive strategies in this study. This is consistent with the literature that inefficient learners often do not use appropriate cognitive strategies in their learning (Kolencik and Hillwig 2011; Pintrich and Groot 1990). Lastly, the high mean scores on the Metacognitive Strategies Survey (above 3) at the beginning of the research did not leave much room for improvement.

Referring to RQ 2 (What was the effect of the interventions on the students' perceptions of metacognitive support?), the findings suggest that there were significant gains in the students' perceptions of their metacognitive support. This implies that majority of the students perceived that their learning environment was oriented towards the development of their metacognitive capabilities. However, the relatively lower mean scores on the studentstudent discourse scale suggest that many students had the perception that they did not discuss how they learn science in class often. It is not known whether this response is because 
they did not get the opportunity to have such discussions or they misused the time given to discuss how they learn science.

As for RQ 3 (What was the effect of the metacognitive interventions on students' achievement in the Light science test?), the students improved in the first tier of the items in the post-test but the gains in the second tier of the items were lower. Therefore, whereas students may give the correct answers (declarative knowledge) in science tests quite often they fail to explain why their answers are correct (procedural knowledge). Students' inability to provide reasons for their answers may become a bigger problem in senior secondary school science where science assessments usually require students to give explanations for scientific phenomena. To measure students' gains in science in relation to metacognition, processed questions should be used because they draw more on metacognitive strategies instead of cognitive strategies. Therefore, they do not require a student to have read the content beforehand. This would be especially useful in the pre-tests which are done before any content has been taught. The use of processed questions is an area that needs exploration, correlating the achievement in such assessments with data from more reliable quantitative metacognitive instruments.

Although there were no significant gains on any of the scales on the Metacognitive Strategy Use Questionnaire (MStQ), there were significant gains on all the scales of the Metacognitive Support Questionnaire $(M S p Q)$. This implies that most of the students perceived their science classroom environment to be metacognitively oriented but did not often employ metacognitive strategies to learn science. This invites speculation as to whether students with low metacognitive capabilities are generally not aware of the range of strategy options that are available to them, or whether they are knowledgeable about their strategy options and just do not want to use them (Phelps, Ellis and Hase 2001). 
Based on the findings of this study, there is a lack of convergent validity between the quantitative research instruments (questionnaires) and qualitative research instruments (interviews) that were used in this study. This implies that measuring students' metacognitive strategies still requires the use of multiple methods until a single reliable instrument is developed. According to Azevedo (2009), metacognitive processes may be automated and the exact nature of metacognitive judgements is still unclear. Therefore, qualitative data from interviews is required to gain a deeper understanding of individual students' metacognitive strategies. Qualitative data still remains the best source of information in small classes because for quantitative data to be reliable large samples are required; consequently it is suggested that reliable and easy-to-use metacognition assessment instruments in the science classroom need to be developed. New methods for assessing students' metacognitive strategies will require thorough examination in order to gain understanding of what these methods precisely measure (Veenman 2011). This will lead to the development of 'designer' teaching programmes that specifically address the metacognitive needs of particular science students in the secondary school science classes.

There were several limitations to the study that precluded the ability to generalise the outcomes to larger populations. The first limitation is that the questions in which students' responses showed significant differences between the pre- and post-tests on light are those that required declarative knowledge. These questions do not elicit responses that indicate development in metacognition. Secondly, interruptions due to school commitments resulted in a break in conducting the interventions that could have affected the momentum with which students were acquiring metacognitive skills. Thirdly, although concept maps were used as a metacognitive intervention, they were not used as assessment tools and yet they could have been valuable assessment tools because they give a visual representation of how learners perceive phenomena. 


\section{References}

Anderson, G. 2004. Fundamentals of Educational Research. London, UK: Routledge-Falmer. Asan, A. 2007. "Concept Mapping in Science Class: A Case Study of Fifth Grade Students." Educational Technology \& Society 10 (1): 186-195.

Azevedo, R. 2009. "Theoretical, Conceptual, Methodological, and Instructional Issues in Research on Metacognition and Self-regulated Learning: A Discussion.” Metacognition and Learning 4 (1): 87-95.

Cartwright-Hatton, S., A. Mather, V. Illingworth, J. Brocki, R. Harrington, and A. Wells. 2002. "Development and Preliminary Validation of Meta-cognitions Questionnaire Adolescent Version.” Anxiety Disorders 18 (2004): 411-422.

Chu, H-E., D. F. Treagust, and A. L. Chandrasegaran. 2009. "A Stratified Study of Students' Understanding of Basic Optics Concepts in Different Contexts Using Two-tier Multiple-choice Items.” Research in Science and Technological Education 27 (3): 253265.

Cook-Sather, A. 2011. "Layered Learning: Student Consultants Deepening Classroom and Life Lessons." Educational Action Research 19 (1): 41-57.

Dutke, S., J. Barenberg, and C. Leopold. 2010. "Learning from Text: Knowing the Test Format Enhanced Metacognitive Monitoring.” Metacognition and Learning 5 (2): 195-206.

Greene, J. A., L-J. Costa, and K. Dellinger. 2011. “Analysis of Self-regulated Learning Processing Using Statistical Models for Count Data.” Metacognition and Learning 6: 275-301.

Hacker, D. J., J. Dunlosky, and A. C. Graser. 1998. Metacognition in Educational Theory and Practice. Mahwah, NJ: Lawrence Erlbaum Associate Publishers.

Hartman, H. J. 2001. Metacognition in Learning and Instruction: Theory, Research and Practice. Dordrecht, Netherlands: Kluwer Academic Publishers. 
Huff, J. D., and J. L. Nietfeld. 2009. "Using Strategy Instruction and Confidence Judgements to Improve Metacognitive Monitoring.” Metacognition and Learning 4 (2): 161-176.

Kolencik, P. L., and S. A. Hillwig. 2011. Encouraging Metacognition: Supporting Learners through Metacognitive Teaching Strategies. New York, NY: Peter Lang Publishing.

Ku, K. Y. L., and I. T. Ho. 2010. "Metacognitive Strategies that Enhance Critical Thinking." Metacognition and Learning 5: 251-267.

Larkin, S. 2006. "Collaborative Group Work and Individual Development of Metacognition in the Early Years." Research in Science Education 36: 7-27

Leutwyler, B. 2009. "Metacognitive Learning Strategies: Differential Development Patterns in High School." Metacognition and Learning 4: 111-123.

Magno, C. 2010. "The Role of Metacognitive Skills in Developing Critical Thinking." Metacognition and Learning 5: 137-156.

McLoughlin, C., and A. Taji, A. (2005). Teaching in the Sciences: Learner-centred Approaches. Binghamton, NY: The Haworth Press, Inc.

Phelps, R., A. Ellis, and S. Hase. 2001. "The Role of Metacognitive and Reflective Learning Processes in Developing Capable Computer Users.” Paper presented at the $18^{\text {th }}$ Annual Conference of the Australasian Society for Computers in Learning in Tertiary Education. (ASCILITE), Melbourne, Australia, December.

Pintrich, P. R. 2000. "Multiple Goals, Multiple Pathways: The Role of Goal Orientation in Learning and Achievement." Journal of Educational Psychology 92 (3): 544-555.

Pintrich, P. R., and E. V. De Groot. 1990. "Motivational and Self-regulated Learning Components of Classroom Academic Performance." Journal of Educational Psychology 82 (1): 33-40.

Ritchhart, R., T. Turner, and L. Hadar. 2009. "Uncovering students' thinking about thinking using concept maps.” Metacognition and Learning 4 (2): 145-159. 
Saab, N., W. R. Van Joolingen, and B. Van Hout-Wolters. 2011. "Support of the collaborative inquiry learning process: influence of support on task and team regulation.” Metacognition and Learning 7: 7-23.

Schellings, G. 2011. Applying Learning Strategy Questionnaires: Problems and Possibilities.” Metacognition and Learning 6: 91-109.

Schraw, G. 2009. "A Conceptual Analysis of Five Measures of Metacognitive Monitoring." Metacognition and Learning 4 (1): 33-45.

Schraw, G., K. J. Crippen, and K. Hartley. 2006. Promoting Self-regulation in Science Education: Metacognition as Part of a Broader Perspective on Learning." Research in Science Education 36: 111-139.

Thomas, G. P. 2003. “Conceptualisation, Development and Validation of an Instrument for Investigating the Metacognitive Orientation of Science Classroom Learning Environments: The Metacognitive Orientation Learning Environment Scale-science (MOLES-S).” Learning Environments Research 6: 175-197.

Thomas, G. P. 2006. "An Investigation of the Metacognitive Orientation of Confucian-heritage Culture and Non-Confucian-heritage Culture Science Classroom Learning Environments in Hong Kong." Research in Science Education 36: 85-109.

Vanides, J., Y. Yin, M. Tomita, and M. A. Ruiz-Primo. 2005. "Using concept maps in the science classroom." Science Scope 28 (8): 27-29.

Veenman, M. V. J. 2011. "Alternative assessment of strategy use with self-report instruments: A discussion.” Metacognition and Learning 6: 205-211.

Veenman, M. V. J. 2012. "Metacognition in Science Education: Definitions, Constituents, and Their Intricate Relation with Cognition.” In Metacognition in Science Education: 
Trends in Current Research, edited by A. Zohar and Y. J. Dori, 21-36. Dordrecht, The Netherlands: Springer.

Veenman, M. V. J., P. Wilhelm, and J. J. Beishuizen. 2004. "The Relation Between Intellectual and Metacognitive Skills from a Developmental Perspective." Learning and Instruction 14 (1): 89-109.

Veenman, M.V. J., and M. A. Spaans. 2005. "Relation Between Intellectual and Metacognitive Skills: Age and Task Differences." Learning and Individual Differences 15 (2): 159-176.

Wilson, N. S., and H. Bai. 2010. “The Relationships and Impact of Teachers' Metacognitive Knowledge and Pedagogical Understandings of Metacognition.” Metacognition and Learning 5: 269-288.

Zimmerman, B. J., and D. H. Schunk. 2001. Self-regulated Learning and Academic Achievement: Theoretical Perspectives. Mahwah, NJ: Erlbaum.

Zohar, A., \& David, A. B. (2008). Explicit teaching of meta-strategic knowledge in authentic classroom situations. Metacognition and Learning, 3, 59-82. (not in the text??)

Zohar, A., and A. B. David. 2009. "Paving a Clear Path in a Thick Forest: A Conceptual Analysis of a Metacognitive Component." Metacognition and Learning 4: 177-195. 
Survey No:

Appendix A: Metacognitive Strategies Questionnaire (MStQ)

Name:

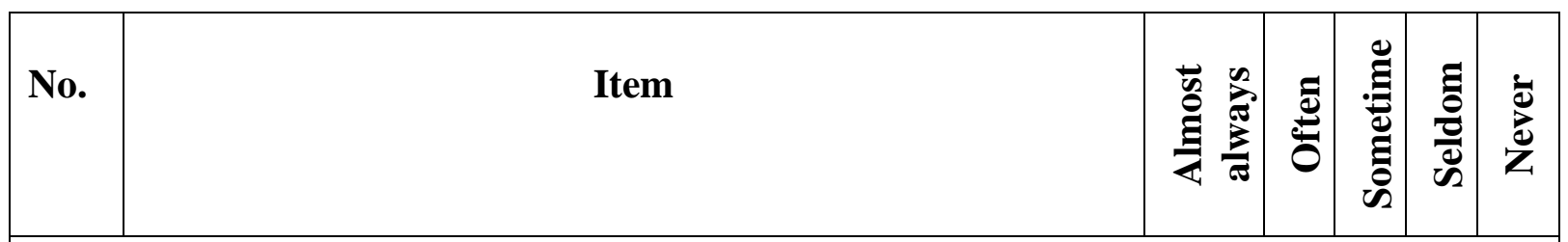

In this science class I:

\begin{tabular}{|l|l|}
\hline 1 & Try to put together the information from class and from the
\end{tabular} book when studying for a test.

2 Try to remember what the teacher has said in class so I can answer the homework correctly.

3 It is hard for me to decide what the main ideas are in what I read.

$4 \quad$ When I study I write important ideas in my own words.

5 I always try to understand what the teacher is saying even if it does not make sense.

$6 \quad$ When I study for a test I try to remember as many facts as I can.

7 When studying, I copy my notes over again to help me remember material.

8 When I study for a test I practice saying the important facts over and over to myself.

9 I use what I have learned from old homework assignments and the textbook to do new assignments.

10 When I am studying a topic, I try to make everything fit together.

11 When I read material for this class, I say the words over and over to myself to help me remember.

12 I outline the chapters in my book to help me study.

13 When reading I try to connect the things I am reading about with what I already know.

When I study for this science class:

14 I ask myself questions to make sure I know the material.

15 I either give up or study only the easy parts when the work is hard.

16 I work on practice exercises and answer end of chapter questions even when I don't have to.

17 I keep working till I finish even when studying materials that are dull and uninteresting.

18 Before I begin studying I think about the things I will need to do to learn.

19 I often find I have been reading for class but don't know what it is all about. 


\begin{tabular}{|l|l|l|l|l|l|}
\hline No. & \multicolumn{1}{|c|}{ Item } & \multicolumn{1}{|c|}{} & & & \\
\hline 20 & $\begin{array}{l}\text { I find that when the teacher is talking I think of other things } \\
\text { and I don't really listen to what is being said. }\end{array}$ & & & \\
\hline 21 & $\begin{array}{l}\text { When I am reading I stop once in a while and go over what I } \\
\text { have read. }\end{array}$ & & & \\
\hline 22 & $\begin{array}{l}\text { I work hard to get a good grade even when I don't like a } \\
\text { class. }\end{array}$ & & & & \\
\hline In preparing for and during this science class I: & & & & \\
\hline 23 & Am constantly aware of my thinking. & & & \\
\hline 24 & Pay close attention to the way my mind works. & & & \\
\hline 25 & Think a lot about my thoughts. & & & & \\
\hline 26 & Constantly examine my thoughts. & & & & \\
\hline 27 & Monitor my thoughts. & & & \\
\hline 28 & $\begin{array}{l}\text { Am aware of the way my mind works when I am thinking } \\
\text { through a problem. }\end{array}$ & & & & \\
\hline
\end{tabular}




\section{Appendix B: Metacognitive Support Questionnaire (MSpQ)}

Survey No:

Date:

Class:

Name:

\begin{tabular}{|c|c|c|c|c|c|c|}
\hline No. & Item & 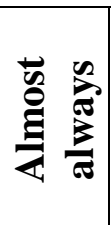 & 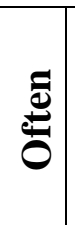 & $\begin{array}{l} \\
\stackrel{\Xi}{\Xi} \\
\stackrel{\Xi}{\Xi} \\
\stackrel{\Xi}{\Xi}\end{array}$ & $\begin{array}{l}\Xi \\
\frac{\partial}{0} \\
\tilde{D}\end{array}$ & 这 \\
\hline \multicolumn{7}{|c|}{ In this science class I am asked by the teacher: } \\
\hline 1 & To think about how to learn science. & & & & & \\
\hline 2 & To explain how I solve science problems. & & & & & \\
\hline 3 & To think about my difficulties in learning science. & & & & & \\
\hline 4 & $\begin{array}{l}\text { To think about how I could become a better learner of } \\
\text { science. }\end{array}$ & & & & & \\
\hline 5 & To try new ways of learning science. & & & & & \\
\hline \multicolumn{7}{|c|}{ In this science class I discuss with others: } \\
\hline 6 & About how they learn science. & & & & & \\
\hline 7 & About how they think when they learn science. & & & & & \\
\hline 8 & About different ways of learning science. & & & & & \\
\hline 9 & About how well they are learning science. & & & & & \\
\hline 10 & How they can improve their learning of science. & & & & & \\
\hline \multicolumn{7}{|c|}{ In this science class students discuss with the teacher about: } \\
\hline 11 & How they learn science. & & & & & \\
\hline 12 & How they think when they learn science. & & & & & \\
\hline 13 & Different ways of learning science. & & & & & \\
\hline 14 & How well they are learning science. & & & & & \\
\hline 15 & How they can improve their learning of science. & & & & & \\
\hline \multicolumn{7}{|c|}{ In this science class: } \\
\hline 16 & $\begin{array}{l}\text { It is alright for students to tell the teacher when they don't } \\
\text { understand science. }\end{array}$ & & & & & \\
\hline 17 & $\begin{array}{l}\text { It is alright for students to ask the teacher why they have to do } \\
\text { a certain activity. }\end{array}$ & & & & & \\
\hline 18 & $\begin{array}{l}\text { It is alright for students to suggest alternative science learning } \\
\text { activities to those proposed by the teacher. }\end{array}$ & & & & & \\
\hline 19 & $\begin{array}{l}\text { It is alright for students to speak out about activities that are } \\
\text { confusing. }\end{array}$ & & & & & \\
\hline 20 & $\begin{array}{l}\text { It is alright for students to speak out about anything that } \\
\text { prevents them from learning. }\end{array}$ & & & & & \\
\hline \multicolumn{7}{|c|}{ In this science class the teacher: } \\
\hline 21 & Encourages students to try to improve the way they learn. & & & & & \\
\hline 22 & Encourages students to try different ways to learn science. & & & & & \\
\hline 23 & Supports students who try to improve their science learning. & & & & & \\
\hline
\end{tabular}




\begin{tabular}{|c|c|c|c|c|c|c|}
\hline No. & Item & 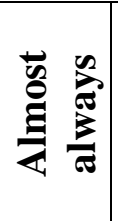 & $\overbrace{0}^{\frac{\pi}{0 ँ}}$ & 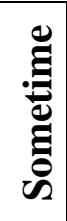 & 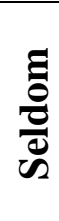 & ż \\
\hline 24 & Supports students who try new ways of learning science. & & & & & \\
\hline 25 & $\begin{array}{l}\text { Encourages students to talk with each other about how they } \\
\text { learn science. }\end{array}$ & & & & & \\
\hline
\end{tabular}

